\title{
Antifouling and Photocatalytic Antibacterial Activity of the AquaSun Coating in Seawater and Related Media
}

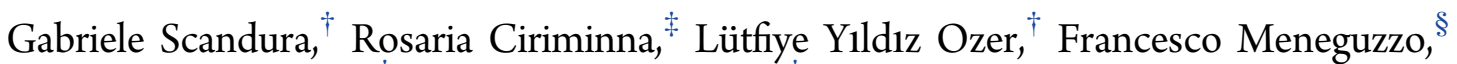 \\ Giovanni Palmisano, ${ }^{*}, \dagger$ and Mario Pagliaro $*, \neq 0$
}

${ }^{\dagger}$ Department of Chemical Engineering, Khalifa University of Science and Technology, Masdar Institute, Masdar City, P.O. Box 54224, Abu Dhabi, United Arab Emirates

${ }^{\ddagger}$ Istituto per lo Studio dei Materiali Nanostrutturati, CNR, via U. La Malfa 153, 90146 Palermo, Italy

${ }^{\S}$ Istituto di Biometeorologia, CNR, via Madonna del Piano 10, 50019 Sesto Fiorentino (FI), Italy

\section{Supporting Information}

ABSTRACT: Prolonged testing of the new xerogel photocatalytic coating AquaSun applied to a surface probe immersed in ocean water irradiated with simulated solar radiation shows excellent action against biofouling. Activated by moderate solar radiation, the organosilica film has also good antimicrobial properties. Considering the high stability, the environmental footprint, and the low cost of this sol-gel marine coating, the technology has significant potential toward replacing conventional antifouling and foul-release coatings with a single product of broad applicability.

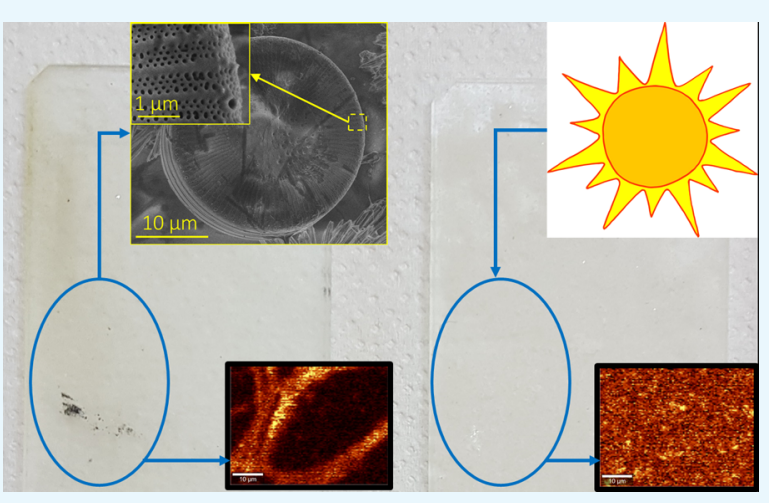

\section{INTRODUCTION}

Every year, more than 80000 tonnes of marine antifouling (AF) paints, mostly copper-based, are used across the world to protect vessels of any size and scope, ${ }^{1}$ posing a serious threat to the environment. Intense research works carried out at both antifouling coating makers and in academic research centers have actually resulted in the development of several environmentally benign alternatives, mostly based on foul-release (FR) polymeric coatings, but also including formulations, whose action is based on less toxic biocides. ${ }^{2-4}$

Foul-release (FR) waterborne xerogel coatings composed of organically modified silica (ORMOSIL) are among the environmentally benign solutions identified. ${ }^{5-7}$ Their action is based on the ability to form a thin hydrophobic protective layer, to which biofouling sticks loosely to be released even at low cruising speed. Their main limitation is due to their limited antifouling action when the vessel is in harbor for prolonged periods.

Aiming to develop a coating capable of providing full protection to ships, recreational boats, and underwater structures against marine biofouling, we have recently reported the promising discovery that nanoflower-like $\mathrm{Bi}_{2} \mathrm{WO}_{6}$ encapsulated in methyl-modified silica shows excellent photocatalytic antifouling action leading to the formation of hydrogen peroxide. ${ }^{8-11}$ Hydrogen peroxide is a strong and clean oxidant decomposing into water and oxygen, ${ }^{12}$ able to rapidly degrade the (bio)organic species adsorbed onto the film, making the surface inhospitable to the settling larvae of fouling organisms, by a free-radical intermediate that prevents the attachment of hard foulants. ${ }^{13}$ This semiconductor is highly active under visible radiation and thus it overperforms $\mathrm{TiO}_{2}$-based semiconductors, which have been proposed in the past for analogous applications. $^{14,15}$

Dubbed AquaSun, the recently developed $\mathrm{Bi}_{2} \mathrm{WO}_{6}$ coating, typically forms a transparent thin film (3 $\mu$ m thick) of methylsilica, in which the particles of the semiconductor are homogeneously encapsulated within the ORMOSIL matrix, retaining their flowerlike nanostructure. Using uracil as representative molecular precursor of biofouling, we showed that under irradiation with solar light, the coating degraded about half of 1 ppm uracil in 3 days. No wolframate leaching was observed into the supernatant solution, even after 3 months immersion and after repeated irradiation cycles. Remarkably, furthermore, the activity degradation rate was found to be linear, pointing to no saturation effects or prolonged absorption of the substrate. Indeed, further investigation using adenine as probe revealed good foul-release properties of the coating, with all adenine adsorbed from a $1 \mathrm{ppm}$ solution being released in $2 \mathrm{~h}$ upon immersion in water, even in the absence of light irradiation. Now, we show the efficiency of this new coating in real-life tests conducted for 122 days in seawater obtained from Al Raha Beach, Abu Dhabi, United Arab Emirates.

Received: August 23, 2017

Accepted: October 23, 2017

Published: November 3, 2017 


\section{MATERIALS AND METHODS}

2.1. Experimental Runs in Seawater. The waterborne coating was sol-gel-derived through hydrolytic polycondensation, under acidic conditions, of a sol containing $50 \mathrm{~mol} \%$ tetraethoxysilane and $50 \mathrm{~mol} \%$ methyl-triethoxysilane, to which flowerlike nanostructured $\mathrm{Bi}_{2} \mathrm{WO}_{6}$ was added $(50 \mathrm{mM})$ as previously described. ${ }^{4}$ Runs were performed in a $2.5 \mathrm{~L}$ beaker using seawater $(1.5 \mathrm{~L})$ placed in contact with glass slides after getting rid of most sand particles through sedimentation. Bare and functionalized glass slides were used under two different conditions: (A) no applied radiation, meaning that only the low diffuse radiation present in the laboratory reached the solution and (B) under intermittent irradiation with $500 \mathrm{~W}$ simulated solar light (LOT Quantum Design LS0606, equipped with a Xenon short-arc lamp and AM1.5G filter). In the latter case, water evaporation was not negligible. Consequently, an aliquot of seawater (around $100 \mathrm{~mL}$ ) was poured in the beaker to replenish the original amount around every 10 days since the beginning of the experiment. The overall experiment lasted 122 days.

In experiment $\mathrm{B}$, the radiation intensities were $2.8 \mathrm{~W} / \mathrm{m}^{2}$ in the wavelength range of $315-400 \mathrm{~nm}$ and $60 \mathrm{~W} / \mathrm{m}^{2}$ in the wavelength range of $450-950 \mathrm{~nm}$. Irradiation was applied every day for the number of hours indicated in Table 1 (total

Table 1. Irradiation Time under Simulated Solar Light for Experiment B

\begin{tabular}{cccc} 
period & $\begin{array}{c}\text { hours per } \\
\text { day }\end{array}$ & $\begin{array}{c}\text { number of } \\
\text { days }\end{array}$ & $\begin{array}{c}\text { total hours of } \\
\text { irradiation }\end{array}$ \\
from day 1 to day 42 & 2.5 & 42 & 105 \\
from day 43 to day 65 & 8.5 & 23 & 195.5 \\
from day 66 to day 122 & 5 & 57 & 285 \\
\hline
\end{tabular}

number of hours under simulated solar light was 585.5). In Supporting Information (Figures S1 and S2), the visible light (VL) radiation intensity (wavelength range: $400-1050 \mathrm{~nm}$ ) in the laboratory during a working day and the visible light irradiation intensity (wavelength range: $400-1050 \mathrm{~nm}$ ) in the laboratory during a public holiday are reported. Radiation intensity was measured with a Delta Ohm 9721 radiometer and the matching probes. The duration of irradiation per day is not constant along the 122 days, but the samples were all exposed to light contemporaneously so that the results are comparable. The characteristics of the seawater were analyzed with a Shimadzu TOC-L total organic carbon (TOC) analyzer, a Delta Ohm $\mathrm{pH}$ $\chi-\mathrm{O}_{2}$ meter (model HD22569.2), an ion chromatography system Dionex ICS-5000, and a HACH 2100AN turbidimeter. Tables 2 and 3 summarize the characteristics of the seawater at the

Table 2. Main Characteristics of the Seawater at the Beginning (Day 0) and End (Day 122) of the Experiment ${ }^{a}$

$\begin{array}{lccc} & \text { day } 0 & \text { day } 122 \text { experiment A } & \text { day } 122 \text { experiment B } \\ \mathrm{pH} & 8.250 & 8.483 & 8.191 \\ \text { conductivity }(\mathrm{mS}) & 50.4 & 53.6 & 64.5 \\ \text { dissolved } \mathrm{O}_{2} & 7.73 & 7.53 & 7.43 \\ \quad(\mathrm{mg} / \mathrm{L}) & & & \\ \mathrm{TC}(\mathrm{mg} / \mathrm{L}) & 26.60 & 26.76 & 25.72 \\ \mathrm{IC}(\mathrm{mg} / \mathrm{L}) & 25.38 & 25.57 & 22.93 \\ \mathrm{TOC}(\mathrm{mg} / \mathrm{L}) & 1.218 & 1.186 & 2.784 \\ \text { turbidity }(\mathrm{NTU}) & 0.130 & 0.226 & 0.407\end{array}$

${ }^{a} \mathrm{TC}=$ total carbon, $\mathrm{IC}=$ inorganic carbon, $\mathrm{TOC}=$ total organic carbon.
Table 3. Ion Concentrations Expressed in $\mathrm{mg} / \mathrm{L}$ in the Seawater at the Beginning (Day 0) and End (Day 122) of the Experiment

\begin{tabular}{llcc} 
& day 0 & day 122 experiment A & day 122 experiment B \\
$\mathrm{Na}^{+}$ & 13400 & 14200 & 30200 \\
$\mathrm{~K}^{+}$ & 3300 & 3570 & 6700 \\
$\mathrm{Mg}^{2+}$ & 169.5 & 183.5 & 348 \\
$\mathrm{Ca}^{2+}$ & 422 & 457 & 845 \\
$\mathrm{Li}^{+}$ & traces & traces & traces \\
$\mathrm{NH}_{4}^{+}$ & 4.4 & 4.9 & 5.0 \\
$\mathrm{Cl}^{-}$ & 28200 & 29700 & 60000 \\
$\mathrm{Br}^{-}$ & 97.5 & 104 & 192.5 \\
$\mathrm{NO}_{3}^{-}$ & 2.45 & 1.43 & 3.15 \\
$\mathrm{SO}_{4}{ }^{2-}$ & 3970 & 4180 & 8870 \\
$\mathrm{~F}^{-}$ & 1.35 & 1.40 & 2.40 \\
\hline
\end{tabular}

beginning (day 0 ) and end (day 122) of the experiments. It can be noticed that the salinity increased significantly at the end of experiment $\mathrm{B}$ due to evaporation of water under irradiation, resulting in a concentration of the ionic species.

2.2. Experimental Runs in Luria-Bertani (LB) Medium. Photocatalytic antimicrobial effect of AquaSun against Escherichia coli was evaluated in Luria-Bertani (LB) medium. In this study, E. coli DH5 $\alpha$, used as model bacteria, was first precultured in $5 \mathrm{~mL}$ of $\mathrm{LB}$ medium for $18 \mathrm{~h}$ at $37^{\circ} \mathrm{C}$ in $\mathrm{LB}$ medium. Prior to the experiments, all glassware were autoclaved for $15 \mathrm{~min}$ at 121 ${ }^{\circ} \mathrm{C}$ to ensure the sterility. An aliquot $(100 \mu \mathrm{L})$ of $E$. coli cell culture was cultured in $15 \mathrm{~mL}$ of $\mathrm{LB}$ medium for $15 \mathrm{~h}$ at $37^{\circ} \mathrm{C}$ and agitated at $120 \mathrm{rpm}$. The experiments to assess photocatalytic antimicrobial effect were carried out using a flat visible 33.1 W light-emitting diode (LED) source emitting at wavelengths greater than $425 \mathrm{~nm}$. The light was then focused onto a glass tube containing a suspension of bacterial cells and bismuth tungstate-based film. During experiments, the antibacterial effect of film against $E$. coli growth was measured every hour by the optical density at $600 \mathrm{~nm}\left(\mathrm{OD}_{600}\right)$ using a UV-visible spectrophotometer (Thermo Fisher Scientific model \#810S UV-vis-Bio). LB medium without bacterial suspension, a bacterial suspension without the photocatalyst, and a bacterial suspension in the presence of bare glass slide were also irradiated as a controls. In addition, the control suspensions and the reaction mixture were kept in the dark to have a dark control. The results were plotted on a semilogarithmic graph to obtain a growth curve as optical density $(Y)$ versus time $(X)$. From the curve, the specific growth rates were calculated.

2.3. Characterization of the Coating. Diffuse reflectance spectra were measured by a UV-vis spectrophotometer (Shimadzu UV-2600) in the wavelength range of 350-750 $\mathrm{nm}$. The photoluminescence (PL) spectra in emission mode with an excitation at $300 \mathrm{~nm}$ were recorded using a PerkinElmer LS 55 spectrometer between 310 and $600 \mathrm{~nm}(200 \mathrm{~nm} / \mathrm{min}$ scan rate $)$. Raman spectra were recorded with a Witec Alpha 300R equipment, with an excitation wavelength of $532 \mathrm{~nm}$ and a laser power of ca. $75 \mathrm{~mW}$. Scans were taken over an extended range $\left(100-2000 \mathrm{~cm}^{-1}\right)$ with $5 \mathrm{~s}$ integration time and 30 accumulations. Raman mapping was done with $0.1 \mathrm{~s}$ integration time. Scanning electron microscopy (SEM) investigation was carried out with an FEI Nova NanoSEM 650 microscope. A CSI Nano-Observer atomic force microscopy (AFM) microscope was operated in amplitude modulation mode, and standard Asylum Research AC160TS-R3 cantilevers $(k \approx 26 \mathrm{~N} / \mathrm{m}, f \approx 300$ 
$\mathrm{kHz}$ ) were used for the AFM experiments. An area of $49 \mu \mathrm{m}^{2}$ of the sample surface was scanned at a rate of $0.75 \ln / \mathrm{s}$.

\section{RESULTS AND DISCUSSION}

3.1. Performance in Seawater. Under solar light, marine phytoplankton microorganisms give place to photosynthesis, providing organic matter for the organisms that comprise the majority of marine life, ${ }^{16}$ consuming inorganic carbon. For this reason, in experiment $\mathrm{B}$, the total organic carbon (TOC) increased and the inorganic carbon (IC) decreased when comparing the initial and final concentrations. Nevertheless, the total carbon (TC) is reduced because the thin film under visible light is able to mineralize organic matter with the formation of carbon dioxide, which evolves from the supernatant solution. ${ }^{1}$

Conversely, in experiment A, the values of TC, IC, and TOC before and after each run are substantially the same, which is due to the insufficient radiation, thereby proving that degradation is due to the photocatalytically formed hydrogen peroxide achievable only by irradiating with (simulated) solar light. When the film is applied on a surface constantly exposed to solar radiation, it continuously produces $\mathrm{H}_{2} \mathrm{O}_{2}$ according to eqs $1-5$, where $\mathrm{h}^{+}$are the holes generated in the valence band of the semiconductor and $\mathrm{e}^{-}$are the electrons formed in the conduction band $^{17}$

$$
\begin{aligned}
& \mathrm{Bi}_{2} \mathrm{WO}_{6}+h \nu \rightarrow \mathrm{Bi}_{2} \mathrm{WO}_{6}\left(\mathrm{e}^{-}(\mathrm{CB})+\mathrm{h}_{(\mathrm{VB})}^{+}\right) \\
& \mathrm{OH}^{-}+\mathrm{h}_{(\mathrm{VB})}^{+} \rightarrow^{\bullet} \mathrm{OH} \\
& \mathrm{O}_{2}+\mathrm{e}^{-}(\mathrm{CB}) \rightarrow \mathrm{O}_{2}^{\bullet-} \\
& \mathrm{O}_{2}^{\bullet-}+\mathrm{H}^{+} \rightarrow \mathrm{HO}_{2}^{\bullet} \\
& 2 \mathrm{HO}_{2}^{\bullet} \rightarrow \mathrm{O}_{2}+\mathrm{H}_{2} \mathrm{O}_{2}
\end{aligned}
$$

Comparison between the UV-vis diffuse reflectance spectra of the bare glass slide and the glass slide functionalized with the AquaSun coating (Figure 1) highlights a minor shift of the latter because, under simulated solar light, the film functionalized with the coating is much cleaner than the unprotected glass.

The effect of the solar light on the glass slide functionalized with the AquaSun thin film is evident in Figure 2, showing that the coated glass, when exposed to the low diffuse radiation present in the laboratory room, undergoes the growth of biomass on its surface because after 4 months (day 122) two significant peaks (around 440 and $675 \mathrm{~nm}$ ) appear in the diffuse reflectance

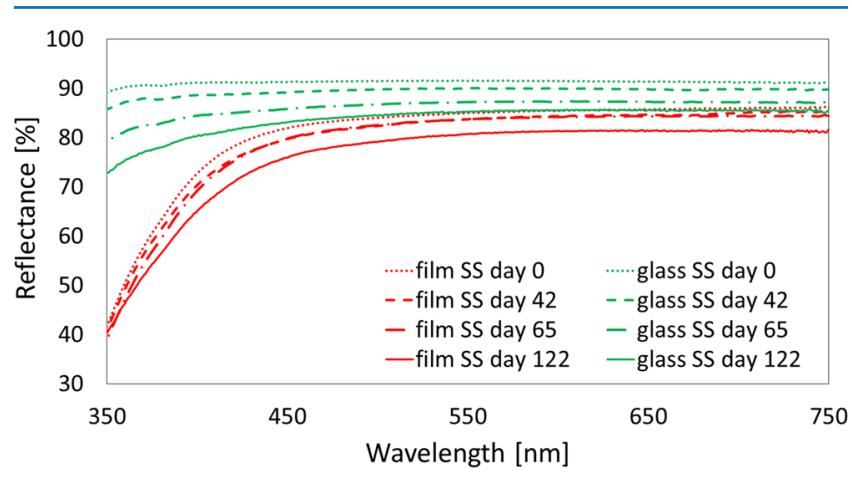

Figure 1. Diffuse reflectance spectra of bare glass and functionalized glass (labeled as "film") in the presence of simulated solar light. SS stands for "solar simulator" and it refers to experiment B.

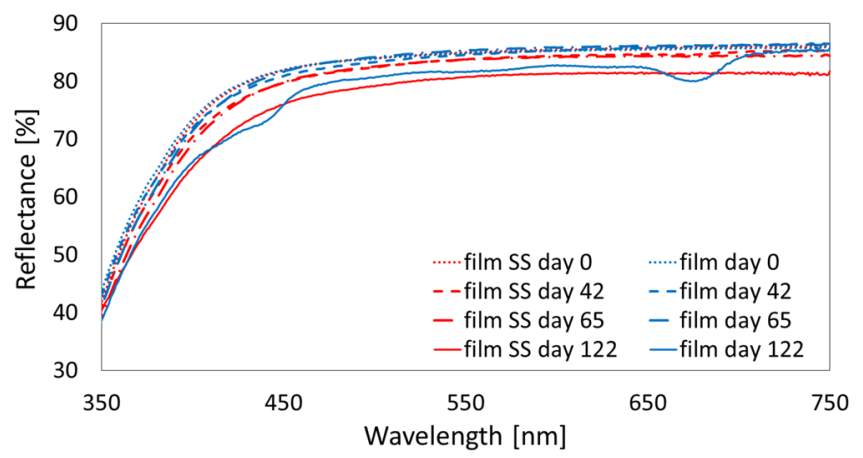

Figure 2. Diffuse reflectance spectra of functionalized glass (labeled as film) in the absence or in the presence of simulated solar light. SS stands for solar simulator and it indicates experiment $\mathrm{B}$.

spectrum. Accordingly, the TC, IC, and TOC values at the end of the test in seawater did not decrease: a crucially important result that was visually confirmed (Figure 3).

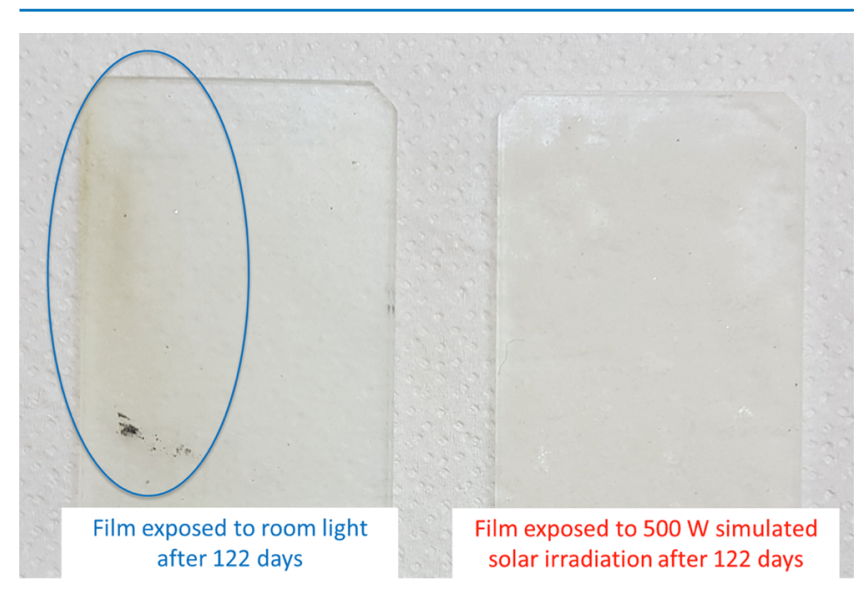

Figure 3. Area of the film (indicated by the blue oval) where a biomass layer deposited because of the low irradiation.

The presence of the biomass also affects the photoluminescence (PL) of the film. The PL spectrum of the functionalized glass shows a peak around $420 \mathrm{~nm}$ (Figure 4), which is clearly stronger when the film was exposed to room light in comparison to the peak shown by the coated glass exposed to simulated solar irradiation. Indeed, it is known that some marine microorganisms, such as algae, can produce photoluminescence

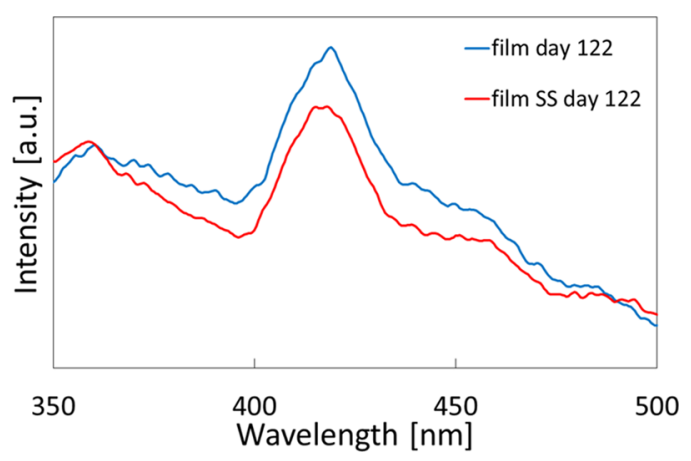

Figure 4. Photoluminescence (PL) spectra of functionalized glass (labeled as film) with an excitation of $300 \mathrm{~nm}$ in the absence or in the presence of simulated solar light. "SS" stands for solar simulator and it refers to experiments $B$. 
emission in the visible region due to the proteins or aromatic amino acid, and their metabolites. ${ }^{18}$

Figure 5 depicts the Raman spectra of both bare and functionalized glass before (day 0) and after the experiments (day 122).

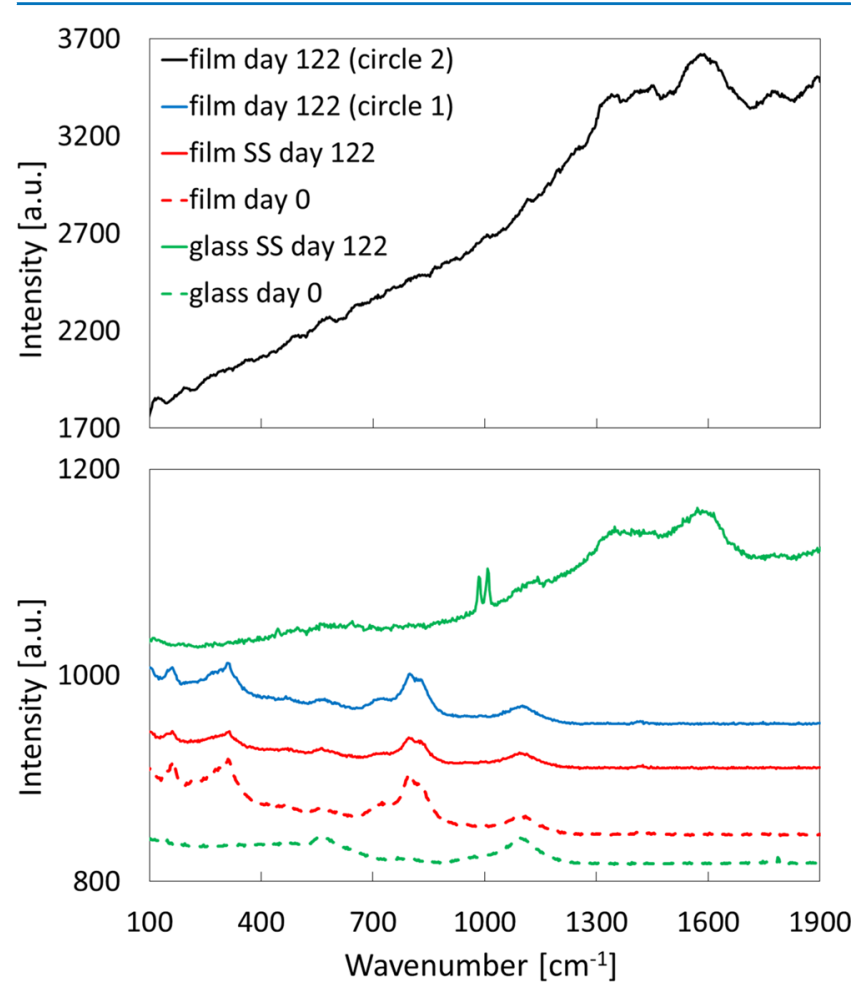

Figure 5. Raman spectra of functionalized (labeled as film) and bare glass before (day 0 ) and after 122 days in the absence and in the presence of simulated solar light. SS stands for solar simulator and it refers to experiments B. The curves related to the "film day 122 " were obtained by pointing Raman laser on the circles 1 and 2 in Figure 6a.

The glass coated with AquaSun coating exhibits three peaks (at ca. 161,311 , and $799 \mathrm{~cm}^{-1}$ ) attributable to $\mathrm{Bi}_{2} \mathrm{WO}_{6}$ encapsulated in the ORMOSIL ${ }^{19}$ and two peaks (around 560 and $1095 \mathrm{~cm}^{-1}$ ) due to the glass substrate.

In experiment $\mathrm{B}$, the functionalized film after 4 months shows the same Raman spectrum as day 0 . On the contrary, the bare glass spectrum displays several new peaks. The film of experiment $\mathrm{A}$ affords two different types of spectra according to where the laser beam is pointed. One (corresponding to circle 1 in Figure 6a) is identical to the spectrum on day 0 . Another (corresponding to circle 2 in Figure 6a) displays a much larger background intensity (top curve in Figure 5). This spectrum results from biomass, which has been produced because of the poor illumination in the room, and is caused by the photoluminescence of the biomass itself (in agreement with Figure 4), which covers completely the signals of $\mathrm{Bi}_{2} \mathrm{WO}_{6}$.

Remarkably, these two populations of spectra obtained from the film irradiated by room light only are clearly distinguishable in Figure 6c, where the Raman mapping of $799 \mathrm{~cm}^{-1}$ peak is displayed: the area where the biomass is abundant gives a stronger intensity, and this is a further confirmation that the far more intense signal of the black curve in Figure 5 is due to the biomass. On the other hand, the Raman mapping of the film exposed to solar light indicates a homogeneous surface, highlighting the absence of biomass in that surface, with a
Raman spectrum which does not change with the area analyzed, and a signal intensity far lower than the one given by the film with accumulated biomass.

Further proof of AquaSun inhibition of the biomass formation on the surface faced to solar light is given by SEM analysis (Figure 7). No relevant differences are observed in the glass coated with AquaSun on day 0 and after 122 days under the conditions of experiment B (Figure 7a,b, respectively). Conversely, the film exposed to room light after 122 days is significantly populated by biomass (Figure 7c). As with regard to the bare (unprotected) glass in experiment B, the SEM image (Figure $7 \mathrm{~d}$ and inset) demonstrates the presence of microorganisms with a circular shape, closely resembling a planktonic diatom.

It is worth reminding that the photocatalytic reaction on the submarine surface is triggered by visible light radiation, which easily penetrates seawater, with reflection at moderate depths accounting to only $5-10 \%$ and with a negligible absorption. ${ }^{20}$

The conclusive evidence of the efficacy of AquaSun under solar light is proved by AFM characterization of the functionalized glasses after experiments (Figure 8). The morphology of the film is affected by the presence of biomass, which can be seen in Figure $8 \mathrm{c}$; also the surface root-mean-square roughness was about $48.5 \mathrm{~nm}$ after experiment $\mathrm{A}$, whereas the same value was $88.0 \mathrm{~nm}$ after experiment $\mathrm{B}$, pointing to a smoothening effect of biomass deposited on the surface.

The matching phase mapping of the two samples showed significant differences. Under simulated solar light, the phase versus counts curve, indicating, namely, the relative abundance of different phases, reported only one main distribution having a maximum around $95^{\circ}$, which can be attributed to the AquaSun coating (see inset of Figure $8 \mathrm{~b}$ ). The slight negative skew is because the coating is a composite material (nanoflower-like $\mathrm{Bi}_{2} \mathrm{WO}_{6}$ encapsulated in methyl-modified silica). On the contrary, after experiment $\mathrm{A}$, the same graph showed two distinct distributions (orange and green areas in the inset of Figure $8 \mathrm{~d}$ ), pointing to the heterogeneity of the surface, where two different materials can be recognized: the AquaSun coating (maximum at $120^{\circ}$ ) and the biomass (maximum at $258^{\circ}$ ). Integration of the curve gives the following ratio: AquaSun 89\%, biomass $11 \%$.

3.2. Performance in Luria-Bertani Medium. The photocatalytic antimicrobial effect of functionalized films was evaluated by the specific growth rate of E. coli in LB medium under visible light (VL) irradiation by comparing a bacterial suspension without the photocatalyst and a bacterial suspension kept in the presence of a bare glass slide, both under visible light irradiation and in the dark. As shown in Table 4, in the dark, the changes in the specific growth rate of E. coli were negligible, indicating that the photocatalyst itself had no antimicrobial effect on the growth rate of $E$. coli. Moreover, a control experiment without photocatalyst, with only E. coli, and E. coli with bare glass under visible light irradiation indicated that the specific growth rate increased compared to E. coli in the dark. On the other hand, the specific growth rate of $E$. coli in the presence of the functionalized glass under visible light was reduced by about $16 \%$ compared to the irradiated bare glass and E. coli.

3.3. Benefits over Current Coatings for Marine Applications. To assist in the process of identifying alternatives to be used as substitutes to replace copper-based antifouling technology, which is of high environmental concern, we provide a brief insight on how the use of AquaSun ensures that copper is not being replaced with equal or more hazardous alternative, 


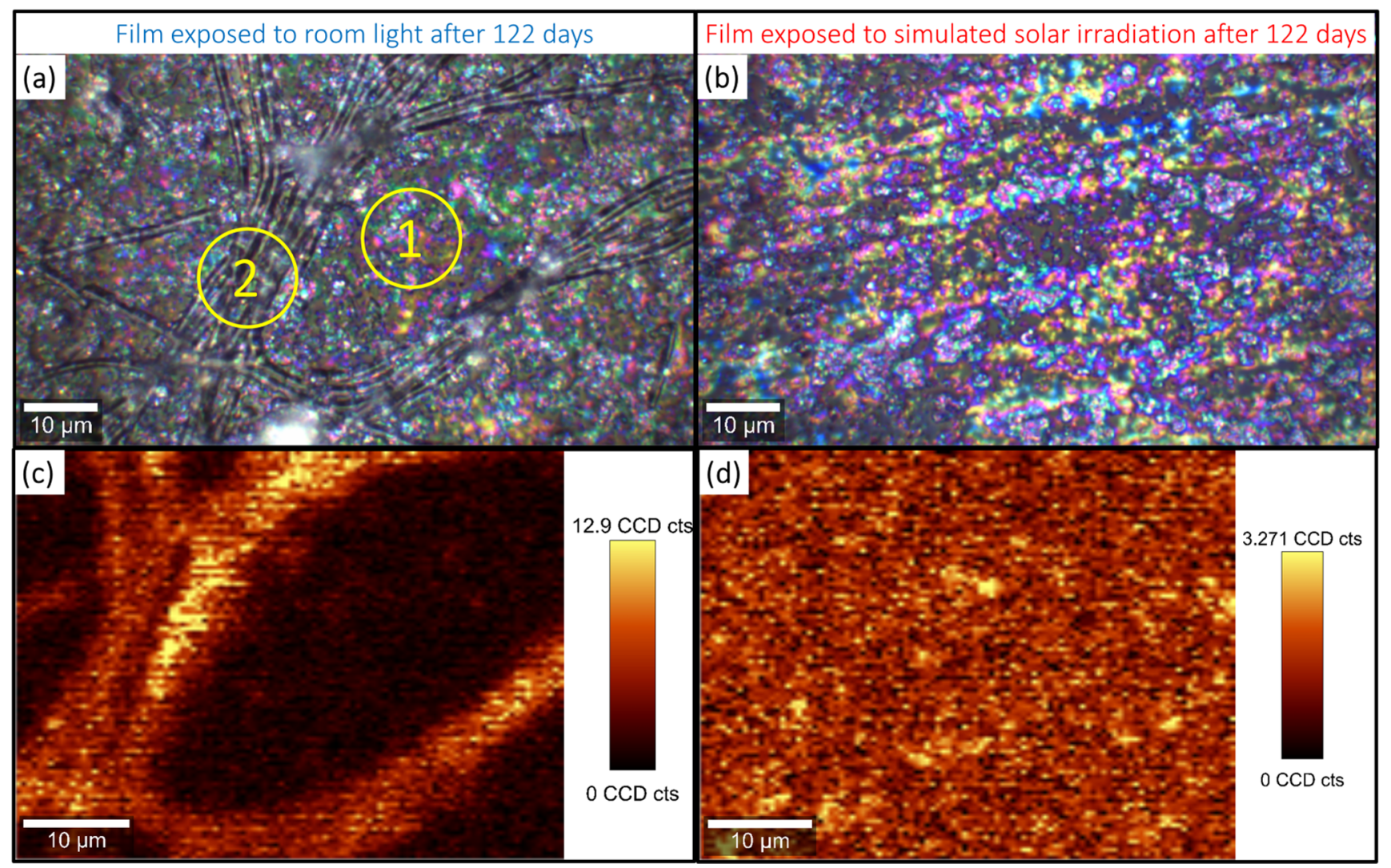

Figure 6. Optical images $\left(100 \times\right.$ magnification) of the films after 122 days in the absence (a) and in the presence (b) of simulated solar light; $799 \mathrm{~cm}^{-1}$ peak Raman mapping (c, d) corresponding to the images in (a) and (b), respectively. Circles 1 and 2 indicate where the laser has been pointed during the recording of the curves labeled as film day 122 in Figure 5. The scale bar is $10 \mu \mathrm{m}$.
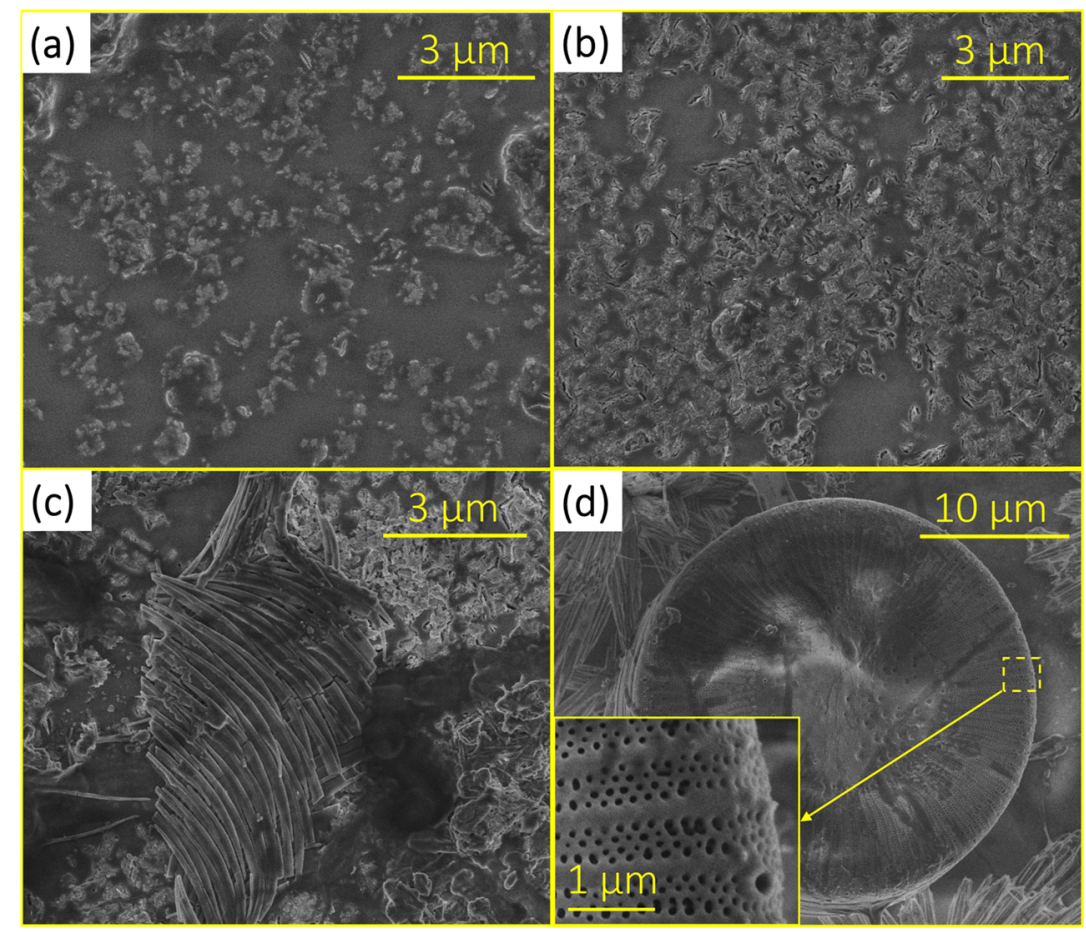

Figure 7. SEM images at $25000 \times$ magnification of the functionalized glass on day 0 (a), after experiment B (b), and after experiment A (c). SEM image at $8000 \times$ magnification of the bare glass after experiment $B(d)$.

thereby getting ahead of new bans or restrictions. For example, phase out of copper-based antifouling paints on recreational vessels less than 65 feet in length by 2020 was adopted by the State of Washington in the United States, where salmon fisheries 


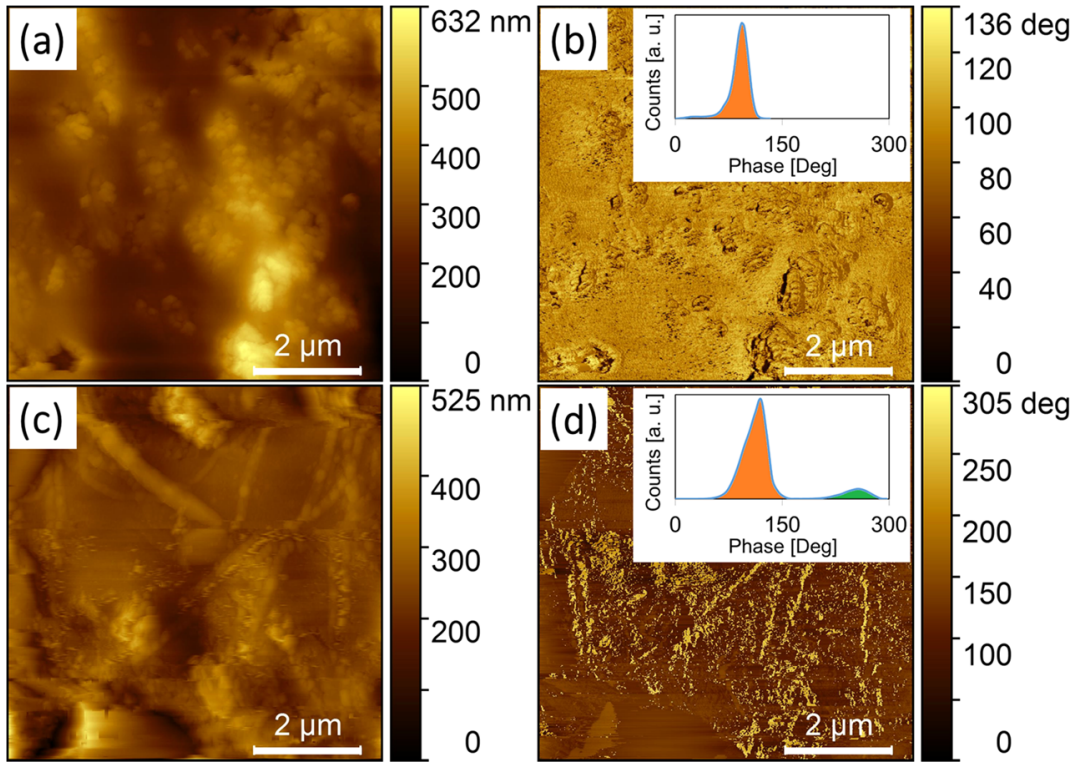

Figure 8. AFM topography and related AFM phase mapping of the functionalized glass after experiment B (a, b) and after experiment A (c, d). The insets show the relative abundance of phases.

Table 4. Specific Growth Rate of Functionalized Glass and Bare Glass against E. coli with and without Visible Light Irradiation

$\begin{array}{lcc}\begin{array}{c}\text { sample } \\ \text { name }\end{array} & \begin{array}{c}\text { specific growth rate in the } \\ \text { dark }\left(\mathrm{min}^{-1}\right)\end{array} & \begin{array}{c}\text { specific growth rate in the presence } \\ \text { of } \mathrm{VL}\left(\mathrm{min}^{-1}\right)\end{array} \\ \begin{array}{c}\text { bare } E . \\ \text { coli }\end{array} & 0.01753 \pm 0.00213 & 0.02026 \pm 0.00569 \\ \text { glass } & 0.01758 \pm 0.00213 & 0.02006 \pm 0.00769 \\ \text { film } & 0.01790 \pm 0.00254 & 0.01673 \pm 0.00267\end{array}$

generate $\$ 3.18$ billion of economic activity each year, supporting over 17000 jobs, with even 2 ppb levels of copper interfering with a salmon's ability to avoid predators and also adversely impacting the ability of fish eggs and fry to develop normally. ${ }^{21}$

The components of the new antifouling product are $\mathrm{Bi}_{2} \mathrm{WO}_{6}$ and the encapsulant methylsilica matrix. The only acute effect recorded in Material Safety Data Sheet for $\mathrm{Bi}_{2} \mathrm{WO}_{6}$ is moderate irritation of the respiratory system following inhalation and low toxicity following ingestion due to its insoluble nature. The complete lack of solubility in water is most promising for what concerns its aquatic toxicity and ecotoxicity (persistence in the environment and bioaccumulation). In general, bismuth is a heavy-metal element with unusually low toxicity, obtained as a byproduct of extraction of other metals, including tungsten, used in many common stomach remedies and cosmetic products. ${ }^{22}$ Tungsten, in its turn, does not constitute an important health hazard. ${ }^{23}$ The tungstate anion $\mathrm{WO}_{4}{ }^{2-}$ isomorph to molybdate antagonizes the normal metabolic action of isomorph molybdate $\mathrm{MoO}_{4}{ }^{2-}$ as metal carrier.

Finally, the low cost, facile preparation with high purity, high stability in various electrolytes, and resistance to photocorrosion makes $\mathrm{Bi}_{2} \mathrm{WO}_{6}$ ideally suited for application in photocatalytic wastewater treatment. ${ }^{24}$ Sol-gel-derived methylsilica is an eminent ORMOSIL. Due to their inertness and excellent textural properties, these materials are used as carriers for drugs and bioactive agents, ${ }^{25}$ with ORMOSIL nanoparticles generally being of little or no toxicity. ${ }^{26}$ Methyl-modified silica is highly stable in water and even more in seawater, whose $\mathrm{pH}$ is limited to the range of $7.5-8.4$, with similar methyl-modified silica coatings functionalized with silver ions, for example, currently being considered for as antibacterial coatings on surgical-grade stainless steel. $^{27}$

\section{OUTLOOK AND CONCLUSIONS}

The AquaSun coating composed of a methyl-modified silica xerogel functionalized with encapsulated $\mathrm{Bi}_{2} \mathrm{WO}_{6}$ effectively prevents the accumulation of biomass on glass in a real seawater environment in prolonged testing lasting up to 4 months. Extensive Raman mapping characterization of the coating highlights the formation of biomass on selected areas of the coated glass probe only when diffuse visible light radiation reaches the surface, whereas unprotected glass was found covered with diatoms. Exposing the coating to visible light radiation using simulated solar light even for a few hours per day $(2.5,5$, and $8 \mathrm{~h}$ for 122 consecutive days) at moderate UV-vis radiation $\left(2.8\right.$ and $60 \mathrm{~W} / \mathrm{m}^{2}$ in the $\mathrm{UV}$ and visible regions, respectively) prevents the formation of any biofilm with a significant reduction in the total amounts of inorganic carbon in water and a concomitant increase of dissolved organic carbon due to ongoing photosynthesis. Moreover, under pure visible radiation, the coated film mitigates bacterial growth in an E. coli culture growth on the coated glass. The mean annual values of the solar radiation flux into the ocean (over the sea surface) vary between $230 \mathrm{~W} \mathrm{~m} / \mathrm{m}^{2}$ above the equator through $40 \mathrm{~W} \mathrm{~m} / \mathrm{m}^{2}$ at the pole, ${ }^{28}$ whereas visible light radiation easily penetrates seawater with negligible absorption and with reflection at moderate depths accounting to only $5-10 \%$.

In general, the high chemical and physical stability of foulrelease sol-gel coatings generally affords long-lasting protection, significantly reducing the need for maintenance on functionalized surfaces. Being a waterborne xerogel organosilica coating, ${ }^{29}$ AquaSun is compatible with most of the surfaces (steel, fiberglass, aluminum, wood, etc.) by spraying or brushing, eliminating the need to handle dangerous paint formulations, curing at room temperature. Forthcoming trials in the open sea will be aimed to identify the optimal application parameters for different navigating vessels. This technology is potentially ready to enter the market soon thanks to its high performance, enabling 
the protection of the aquatic environment and ultimately human health, at the same time preserving surfaces from fouling. These results, in conclusion, may open the route to the future employment of the AquaSun coating sol-gel technology for the protection of different surfaces constantly submerged in sea, lake, and river waters.

\section{ASSOCIATED CONTENT}

\section{(5 Supporting Information}

The Supporting Information is available free of charge on the ACS Publications website at DOI: 10.1021/acsomega.7b01237.

Visible light radiation intensity (wavelength range: 400$1050 \mathrm{~nm}$ ) in the laboratory during a working day, visible light irradiation intensity (wavelength range: 400-1050 $\mathrm{nm}$ ) in the laboratory during a public holiday, and the emission spectrum of the visible LED lamp used throughout this work (Figures S1-S3, respectively) (PDF)

\section{AUTHOR INFORMATION}

\section{Corresponding Authors}

*E-mail: gpalmisano@masdar.ac.ae (G.P.).

*E-mail: mario.pagliaro@cnr.it (M.P.).

ORCID 1

Giovanni Palmisano: 0000-0001-9838-6252

Mario Pagliaro: 0000-0002-5096-329X

Notes

The authors declare no competing financial interest.

\section{ACKNOWLEDGMENTS}

This article is dedicated to Dr. Valerica Pandarus on the occasion of her Ph.D. from Laval University. Drs. Ahmed F. Yousef, Lina F. Yousef, Shadi W. Hasan, and Hector H. Hernandez (Khalifa University, Abu Dhabi) are acknowledged for enabling the use of their lab facilities.

\section{REFERENCES}

(1) Williams, D. Challenges in Developing Antifouling Coatings; IMarEST: London, 2010.

(2) Ciriminna, R.; Bright, F.-V.; Pagliaro, M. Ecofriendly Antifouling Marine Coatings. ACS Sustainable Chem. Eng. 2015, 3, 559-565.

(3) Dobretsov, S.; Thomason, J. C. The Development of Marine Biofilms on Two Commercial Non-Biocidal Coatings: A Comparison Between Silicone and Fluoropolymer Technologies. Biofouling 2011, 27, 869-880.

(4) Yong, H.-E.; Krishnamoorthy, K.; Hyun, K.-Y.; Kim, S.-J. Preparation of $\mathrm{ZnO}$ Nanopaint for Marine Antifouling Applications. J. Ind. Eng. Chem. 2015, 29, 39-42.

(5) Detty, M.-R.; Ciriminna, R.; Bright, F.-V.; Pagliaro, M. Environmentally Benign Sol-Gel Antifouling and Foul-Releasing Coatings. Acc. Chem. Res. 2014, 47, 678-687.

(6) Efimenko, K.; Finlay, J.; Callow, M.-E.; Callow, J.-A.; Genzer, J. Development and Testing of Hierarchically Wrinkled Coatings for Marine Antifouling. ACS Appl. Mater. Interfaces 2009, 1, 1031-1040.

(7) Bennett, S.-M.; Finlay, J. A.; Gunari, N.; Wells, D. D.; Meyer, A. E.; Walker, G. C.; Callow, M.-E.; Callow, J.-A.; Bright, F.-V.; Detty, M.-R. The Role of Surface Energy and Water Wettability in Aminoalkyl/ fluorocarbon/hydrocarbon-modified Xerogel Surfaces in the Control of Marine Biofouling. Biofouling 2009, 26, 235-246.

(8) Scandura, G.; Ciriminna, R.; Xu, Y.-J.; Pagliaro, M.; Palmisano, G. Nanoflower-Like $\mathrm{Bi}_{2} \mathrm{WO}_{6}$ Encapsulated in ORMOSIL as a Novel Photocatalytic Antifouling and Foul Release Coating. Chem. - Eur. J. 2016, 22, 7063-7067.
(9) Zhang, Y.; Zhang, N.; Tang, Z.-R.; Xu, Y.-J. Identification of $\mathrm{Bi}_{2} \mathrm{WO}_{6}$ as a Highly Selective Visible-light Photocatalyst Toward Oxidation of Glycerol to Dihydroxyacetone in Water. Chem. Sci. 2013, 4, $1820-1824$.

(10) Zhang, Y.; Ciriminna, R.; Palmisano, G.; Xu, Y.-J.; Pagliaro, M. Sol-gel Entrapped Visible Light Photocatalysts for Selective Conversions. RSC Adv. 2014, 4, 18341-18346.

(11) Zhang, Y.; Xu, Y.-J. $\mathrm{Bi}_{2} \mathrm{WO}_{6}$ : a Highly Chemoselective Visible Light Photocatalyst Toward Aerobic Oxidation of Benzylic Alcohols in Water. RSC Adv. 2014, 4, 2904-2910.

(12) Ciriminna, R.; Albanese, L.; Meneguzzo, F.; Pagliaro, M. Hydrogen Peroxide: A Key Chemical for Today's Sustainable Development. ChemSusChem 2016, 9, 3374-3381.

(13) Olsen, S.-M.; Kristensen, J.-B.; Laursen, B.-S.; Pedersen, L.-T.; Dam-Johansen, K.; Kiil, S. Antifouling Effect of Hydrogen Peroxide Release from Enzymatic Marine Coatings: Exposure Testing under Equatorial and Mediterranean Conditions. Prog. Org. Coat. 2010, 68, $248-257$.

(14) Yoshioka, K.; Okuda, T.; Fujii, H.; Kamimoto, Y.; Kamiya, H. Effect of $\mathrm{TiO}_{2}$ Nanoparticles Aggregation in Silicate Thin Coating Films on Photocatalytic Behavior for Antifouling Materials. Adv. Powder Technol. 2013, 24, 886-890.

(15) Kwak, S.-Y.; Kim, S.-H.; Kim, S.-S. Hybrid Organic/Inorganic Reverse Osmosis (RO) Membrane for Bactericidal Anti-Fouling. 1. Preparation and Characterization of $\mathrm{TiO}_{2}$ Nanoparticle Self-Assembled Aromatic Polyamide Thin-Film-Composite (TFC) Membrane. Environ. Sci. Technol. 2001, 35, 2388-2394.

(16) Falkowski, P. Ocean science: The power of plankton. Nature 2012, 483, S17-S20.

(17) Zhang, N.; Ciriminna, R.; Pagliaro, M.; Xu, Y.-J. Nanochemistryderived $\mathrm{Bi}_{2} \mathrm{WO}_{6}$ nanostructures: towards production of sustainable chemicals and fuels induced by visible light. Chem. Soc. Rev. 2014, 43, 5276-5287.

(18) Determann, S.-S.; Lobbes, J.-M.; Reuter, R.; Rullkötter, J. Ultraviolet fluorescence excitation and emission spectroscopy of marine algae and bacteria. Mar. Chem. 1998, 62, 137-156.

(19) Phuruangrat, A.; Dumrongrojthanath, P.; Ekthammathat, N.; Thongtem, S.; Thongtem, T. Hydrothermal Synthesis, Characterization, and Visible Light-Driven Photocatalytic Properties of $\mathrm{Bi}_{2} \mathrm{WO}_{6}$ Nanoplates. J. Nanomater. 2014, 1, No. 138561.

(20) McMaster, D.-M.; Bennett, S.-M.; Tang, Y.; Finlay, J.-A.; Kowalke, G.-L.; Nedved, B.; Bright, F.-V.; Callow, M.-E.; Callow, J.-A.; Wendt, D.E.; Hadfield, M.-G.; Detty, M.-R. Antifouling Character of 'Active' Hybrid Xerogel Coatings with Sequestered Catalysts for the Activation of Hydrogen Peroxide. Biofouling 2009, 25, 21-33.

(21) Washington State Legislature. Recreational Water Vessels, Antifouling Paints; Chapter 70.300. http://apps.leg.wa.gov/Rcw/ default.aspx? cite $=70.300 \&$ full $=$ true.

(22) Krüger, J.; Winkler, P.; Lüderitz, E.; Lück, M.; Wolf, H.-U. Bismuth, Bismuth Alloys, and Bismuth Compounds. Ullmann's Encyclopedia of Industrial Chemistry; Wiley-VCH: Weinheim, 2003.

(23) Leffler, P. E.; Kazantzis, G. Tungsten. In Handbook on the Toxicology of Metals, 4th ed.; Nordberg, G. F., Fowler, B. A., Nordberg, M., Eds.; Elsevier: Amsterdam, 2016; Chapter 58.

(24) Girish Kumar, S.; Koteswara Rao, K.-S.-R. Tungsten-based nanomaterials $\left(\mathrm{WO}_{3} \& \mathrm{Bi}_{2} \mathrm{WO}_{6}\right)$ : modifications related to charge carrier transfer mechanisms and photocatalytic applications. Appl. Surf. Sci. 2015, 355, 939-958.

(25) Roy, I.; Kumara, P.; Kumar, R.; Ohulchanskyy, T.-Y.; Yong, K.-T.; Prasad, P.-N. Ormosil nanoparticles as a sustained-release drug delivery vehicle. RSC Adv. 2014, 4, 53498-53504.

(26) Kumar, D.; Prashant, C. K.; Kumar Dind, A.; Mitra, S. Toxicity Assessment of Ormosil Nanoparticles. In Nano BioMaterials; Rajendran, V., Prabu, P., Geckeler, K. E., Eds.; Bloomsbury Publishing India: New Delhi, 2014.

(27) Procaccini, R.; Bouchet, A.; Pastore, J.-I.; Studdert, C.; Ceré, S.; Pellice, S. Silver-functionalized methyl-silica hybrid materials as antibacterial coatings on surgical-grade stainless steel. Prog. Org. Coat. 2016, 97, 28-36. 
(28) Pickard, G. L.; Emery, W. J. Descriptive Physical Oceanography: An Introduction, 5th ed.; Pergamon Press: Oxford, 1990.

(29) Detty, M.-R.; Ciriminna, R.; Bright, F.-V.; Pagliaro, M. Xerogel Coatings Produced by the Sol-Gel Process as Anti-Fouling, FoulingRelease Surfaces: From Lab Bench to Commercial Reality. ChemNanoMat 2015, 1, 148-154. 